\title{
A Comparison of Rainfall, Outgoing Longwave Radiation, and Divergence over the Amazon Basin
}

\author{
Brant Liebmann,* José A. Marengo, ${ }^{+}$John D. Glick,* Vernon E. Kousky,\# \\ IllanA C. WAINER, @ AND Oswaldo MASSAMBANI \& \\ *Climate Diagnostics Center, University of Colorado, Boulder, Colorado \\ ${ }^{+}$Centre for Weather Prediction and Climate Studies, National Insitute for Space Studies, Cachoeira Paulista, Brazil \\ ${ }^{*}$ Climate Prediction Center, NCEP/NWS/NOAA, Washington, D.C.

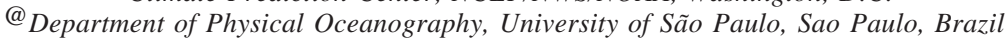 \\ \&Department of Atmospheric Sciences, University of São Paulo, Sao Paulo, Brazil
}

(Manuscript received 26 June 1997, in final form 5 November 1997)

ABSTRACT

\begin{abstract}
Observed rainfall, outgoing longwave radiation (OLR), divergence, and precipitation from the reanalysis project of the National Centers for Environmental Prediction and the National Center for Atmospheric Research are compared over the Amazon Basin. The spatial pattern of the mean and the phase of the annual cycle generally compare well, except that the amplitude of the annual cycle of model precipitation is much smaller than observed. On 10-30-day timescales, it is shown that averaging stations within a $5^{\circ}$ radius is approximately equivalent to total wavenumber 20 (T20) spatial scale, although it is more important to have a high density of stations than an exact match of spatial scales. Ideally, there should be one station per $20000 \mathrm{~km}^{2}$. On 10-30-day scales, observed rainfall is best correlated with OLR. Correlations between OLR and 150-mb divergence are larger than between observed rainfall and divergence or between rainfall and model precipitation. For example, if 10 30-day filtered OLR and divergence are truncated at T20 and rainfall is averaged to include stations within a $5^{\circ}$ radius, OLR is correlated with rainfall at about -0.6 , OLR is correlated with divergence at about -0.35 , and rainfall is correlated with divergence at about 0.2. At least part of the lack of correlation is due to inadequate spatial sampling of rainfall. Correlations improve with larger spatial scale. The major seasonal transitions from dry to rainy regimes are captured well by OLR but not by the model quantities. The mean diurnal cycle is represented reasonably by $150-\mathrm{mb}$ divergence.
\end{abstract}

\section{Introduction}

The Amazon Basin supports one of the three quasistationary centers of intense near-equatorial convection and is the largest and most intense land-based convective center. During the Southern Hemisphere summer when convection is best developed, the Amazon Basin is one of the wettest regions on earth.

Over the Amazon Basin, as well as in other convective regions of the near-equatorial Tropics, low values of outgoing longwave radiation (OLR), abundant rainfall, and enhanced upper-level divergence are thought of almost interchangeably as denoting regions of deep convection. While accurate estimates of rainfall are of direct local importance, a precise knowledge of the divergence field is important on the global scale through its connection to the vorticity budget (e.g., Sardeshmukh and Hoskins 1987).

As with most of the Tropics, the meteorology of the

Corresponding author address: Dr. Brant Liebmann, CIRES, University of Colorado, Campus Box 449, Boulder, CO 80309-0449.

E-mail: bl@cdc.noaa.gov
Amazon Basin is not well observed. There are few upper-air stations from which to calculate divergence directly and rainfall must be observed at high spatial resolution to be accurate on the large scale (e.g., Hudlow 1979). Furthermore, rainfall observations are not reported in a timely manner and there are large areas of the Amazon Basin without coverage. Current efforts, such as the Large Scale Biosphere Atmosphere Experiment in the Amazon Basin (Nobre et al. 1996) and the Variability of the American Monsoon Project (C. R. Mechoso 1997, personal communication), will improve our understanding of the physical mechanisms producing rainfall in the region.

The purpose of this report is to compare estimates of OLR, divergence, and rainfall in the Amazon Basin. The immediate motivation is that we plan to document the onset of the rainy season in that region; therefore, the emphasis is on timescales of less than a month.

OLR has been compared to rainfall using monthly and seasonal means (e.g., Arkin and Meisner 1987) and on shorter timescales (e.g., Morressey 1986). The linear relationships have been deemed reasonable, giving rise to the use of OLR by itself to quantitatively estimate precipitation (e.g., Motell and Weare 1987; Yoo and 
Carton 1988), and to form spatially and temporally continuous datasets by combining OLR with available rain gauge reports (e.g., Xie and Arkin 1998), and by combining OLR with other parameters as well (e.g., Adler et al. 1994; Huffman et al. 1995).

OLR is also often used as a surrogate for upper-level divergence (e.g., Chelliah et al. 1988). Divergence, especially in the Tropics, is impossible to derive directly because of the dearth of upper-air stations, so one must rely on an assimilation model. Unfortunately, the accuracy of tropical divergence derived from global analyses historically has been suspect, at least partly because of changes in assimilation schemes with time. Comparisons of divergence fields from various meteorological centers have shown large differences between different estimates (e.g., Trenberth and Olson 1988; Sardeshmukh and Liebmann 1993); thus, OLR often is deemed a more reliable indicator of divergence than that derived from global wind analyses.

The National Centers for Environmental Prediction (NCEP) reanalysis presents an opportunity to study phenomena of meteorological interest, including divergence and model-derived precipitation, using a complete record that has been assimilated with a temporally consistent scheme (e.g., Kalnay et al. 1996). Many observations are included in this assimilation that were not included in the original operational analysis. The accuracy of the NCEP divergence, however, is still subject to question.

\section{Data}

\section{a. NCEP reanalysis and OLR}

The NCEP reanalysis model (e.g., Kalnay et al. 1996) is a spectral sigma surface model run at a resolution of total wavenumber 62 (T62). Divergence fields have been interpolated to pressure surfaces at T35 resolution. We interpolate these evenly spaced gridded fields to a Gaussian grid and then spectrally truncate them in order to facilitate examination of varying spatial scales. NCEP precipitation fields are available on a Gaussian grid. The reanalysis data extend from 1979 to 1994 . Unless stated otherwise, the four times per day fields have been reduced to 5-day averages. We also have produced corresponding pentads of OLR. Missing values of OLR have been interpolated, primarily in time (Liebmann and Smith 1996).

\section{b. Rainfall}

To estimate rainfall, we have acquired a set of daily rainfall accumulations scattered throughout the Amazon Basin from the archives of the Brazilian Departmento Nacional de Aguas e Energia Eletrica. We consider observations from 127 stations whose record extends from 1979 to 1996 (locations shown in Fig. 4). Missing are $12.5 \%$ of the daily observations.

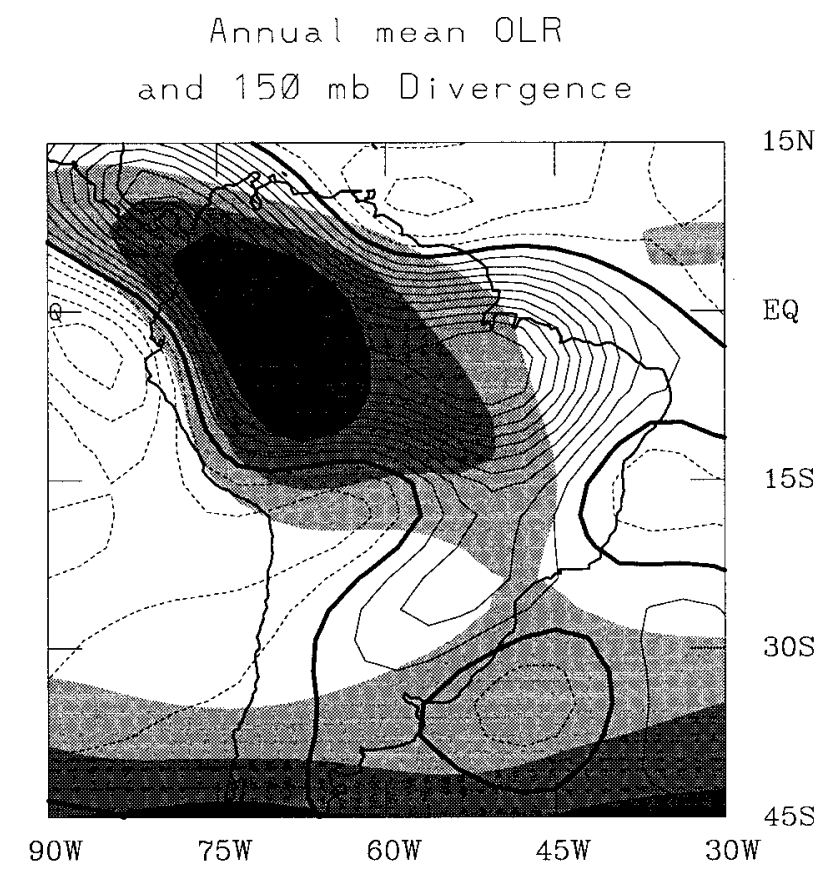

FIG. 1. Annual mean OLR (light shading denotes values less than $240 \mathrm{~W} \mathrm{~m}^{-2}$, medium shading denotes values less than $230 \mathrm{~W} \mathrm{~m}^{-2}$, and dark shading denotes values less than $220 \mathrm{~W} \mathrm{~m}^{-2}$ ) and divergence (contour interval is $0.5 \times 10^{-6}$, with negative contours dashed, and zero contour thick).

We also use a set of high quality measurements of precipitation from the Anglo-Brazilian Amazonian Climate Observation Study (ABRACOS) experiment (Shuttleworth et al. 1991). These data were collected and made available by the U.K. Institute of Hydrology and the Centro de Previsão de Tempo e Estudos Climáticos of the Instituto Nacional de Pesquisas Espaciais, Brazil. ABRACOS is a collaboration between the Agencia Brasileira de Cooperacao and the U.K. Overseas Development Administration. Although these observations are of limited value because there are just three sites (with each site containing an instrument in both a top of the forest canopy and a deforested location), and their record is short, ranging from 3 to 4 years, they are useful in deducing the statistical aspects of diurnal cycle (see Fig. 12).

\section{Results}

a. Mean and annual cycle of OLR, divergence, and NCEP precipitation

Although subseasonal timescales are of particular interest in the present study, the mean and annual cycle serve as benchmarks for any comparison; if there is no correspondence between the annual cycle of OLR, divergence, and precipitation, it is pointless to compare shorter timescales. Figure 1 shows annual mean OLR and NCEP divergence at $150 \mathrm{mb}$. We expect a (negative) correspondence between the two quantities, as large- 
OLR vs Mode! Precipitation

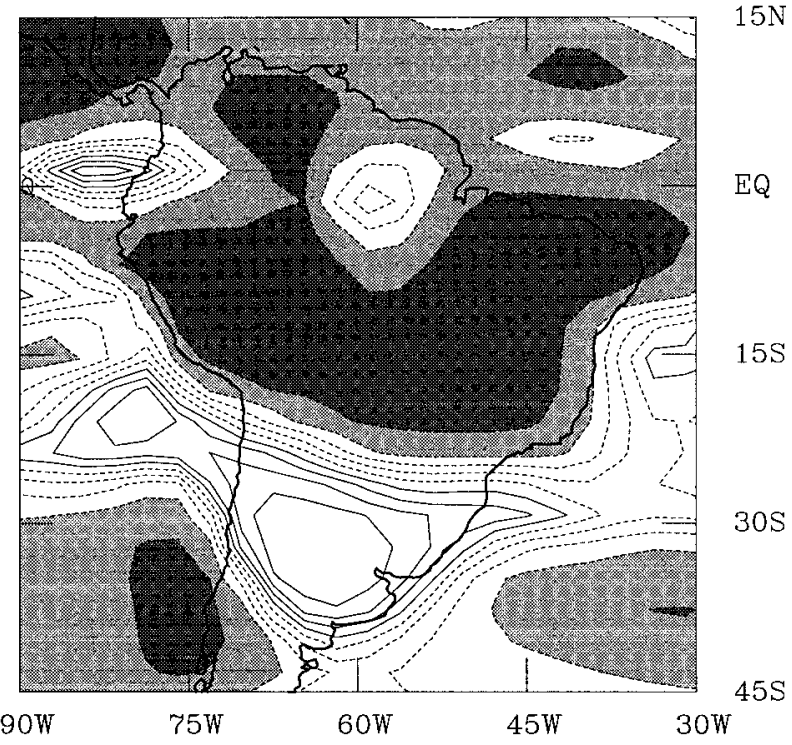

FIG. 2. Correlation between 16-yr pentad climatology of OLR and model precipitation. Fields are truncated at T20 prior to calculating correlation. Contours start at 0.1 with an interval of 0.2 . Negative contours are dashed. Correlations between -0.7 and -0.9 are shaded lightly and those less than -0.9 are shaded darkly.

scale ascending motion should result in both upper-level divergence and high cloud tops, resulting in low OLR. Over the Amazon Basin, 150 mb produces the best annual mean correspondence with OLR, and it will be shown that it also corresponds best to OLR on other timescales. There is a reasonable correspondence between the two quantities over most of the Amazon Basin, with maxima in divergence corresponding to minima in OLR. In the eastern Amazon extending into northeast Brazil, however, there is a local maximum in divergence that does not appear in the OLR field. There is little divergence at $150 \mathrm{mb}$ in the eastern Pacific intertropical convergence zone because divergence associated with relatively low OLR seems to be occurring at a level lower than $150 \mathrm{mb}$. The mean NCEP precipitation field (not shown) corresponds almost exactly to $150-\mathrm{mb}$ divergence, including the lobe that extends to the east.

The Amazon Basin exhibits a strong annual cycle in OLR (e.g., Horel et al. 1989), with a minimum during the rainy season of austral summer. Thus it is expected that divergence and precipitation should undergo a corresponding annual cycle. Figure 2 shows the correlation between the climatological pentads of OLR and NCEP precipitation, both truncated at T20. The correlation is large everywhere over the Amazon, except for a point near $1^{\circ} \mathrm{S}, 60^{\circ} \mathrm{W}$. The pattern is similar to that found when NCEP precipitation is correlated with 150 -mb divergence (not shown), except that the two model variables are correlated at a slightly higher level. The correlation between OLR and 150-mb divergence is less than -0.8

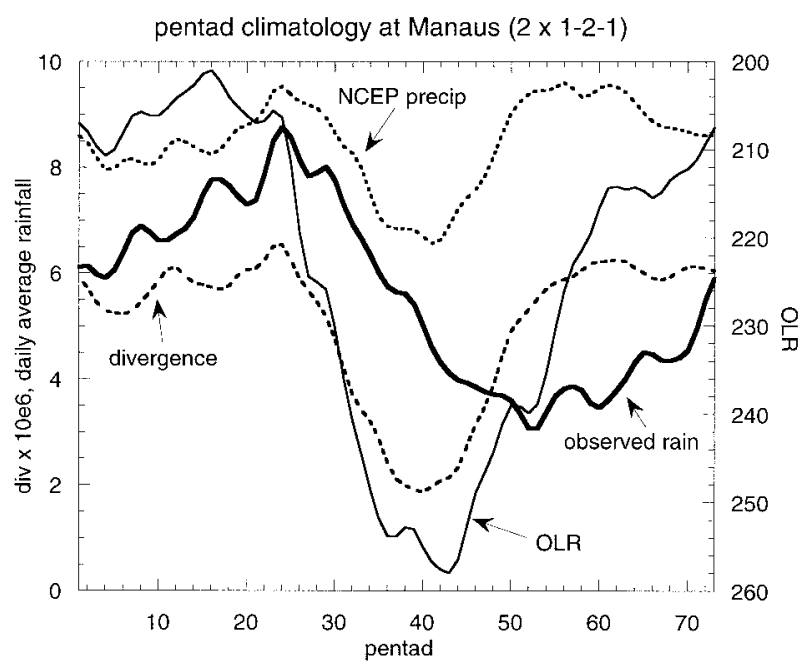

FIG. 3. Pentad climatology of $150-\mathrm{mb}$ divergence, model precipitation, observed rainfall, and OLR centered at $1.4^{\circ} \mathrm{S}, 59.1^{\circ} \mathrm{W}$ (near Manaus). Gridded quantities have been truncated at T20 prior to making time series. Observed rainfall includes all stations with a $5^{\circ}$ radius. Series has been filtered with two passes of a 1-2-1 filter before plotting.

throughout the Amazon, including over the eastern Amazon, where mean divergence appears to be too strong (Fig. 1).

Figure 3 shows pentad climatology time series for all variables of interest at $1.4^{\circ} \mathrm{S}, 60^{\circ} \mathrm{W}$. The time series have been smoothed with two passes of a 1-2-1 running filter. Maximum rainfall occurs around the end of April and the minimum is in mid-September. OLR and divergence capture the peak in rainfall well but both predict a minimum in precipitation early compared to rainfall. NCEP precipitation shows two maxima, such that the secondary peak occurs around the time of the minimum in observed rainfall, resulting in a near-zero correlation between the two. While the peak amounts agree, the amplitude of the annual cycle in NCEP precipitation is quite small compared to that observed. At other locations within the Amazon the phase of NCEP and observed precipitation agree better, but the amplitude of NCEP is still too small.

\section{b. The 10-30-day comparison}

Past studies of Amazonian convection (e.g., Horel et al. 1989; Kousky 1988) have employed pentad averages in order to minimize synoptic variability. We form pentads and spectrally truncate these to include periods up to 30 days. If we compare this time series to that from a Lanczos filter (Duchon 1979) with half-power at periods of 10 and 30 days (Fig. 4), we find an excellent correspondence (correlations everywhere exceeding 0.8 ). Thus for ease of computation, and to minimize problems associated with occasional missing rainfall data, we consider pentads that have been spectrally truncated in this manner as 10-30-day bandpassed data. 


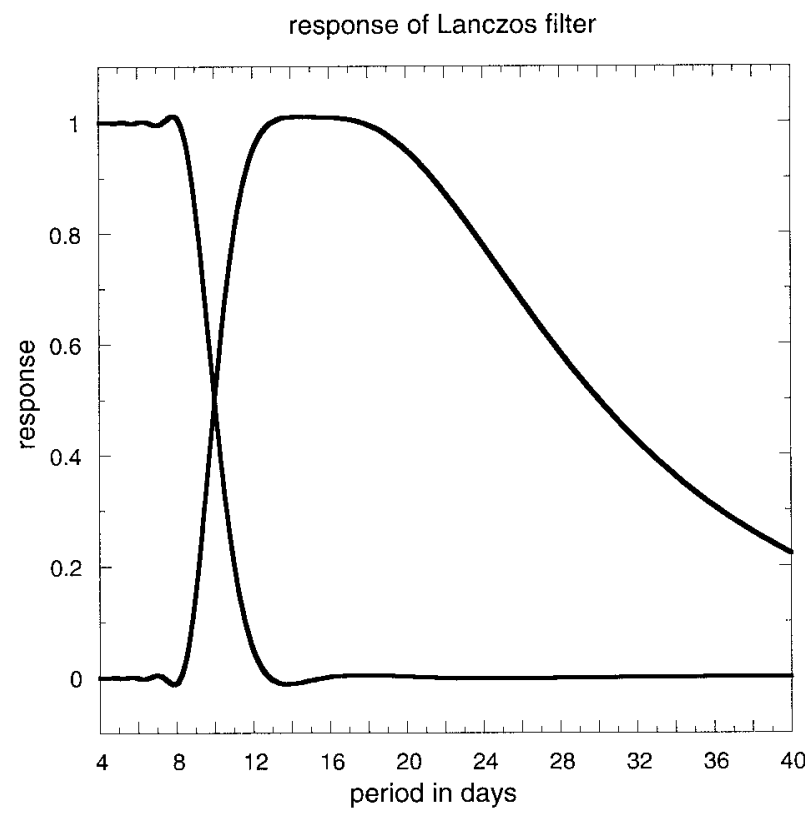

FIG. 4. The ratio of the Lanczos filtered Fourier amplitude in the 10-30- and 2-10-day bands to the unfiltered Fourier amplitude as a function of period.

Figure 5 shows the grid points we have chosen to analyze (see caption for exact locations). The sites are chosen to represent the different regimes within the Amazon Basin (e.g., Marengo 1995). The exact locations were chosen to maximize the number of stations within the rainfall observing network that surround the grid point. The sites are not independent; the correlations of the same variable at different locations is often larger than the correlation between different variables at the same location.

Figure 5 also gives a rough idea of the spatial scale under present scrutiny. The entire field was set to zero, with the exception of one grid point, and then the field was truncated spectrally at T20. The large shaded circle represents the area that has amplitude of at least onehalf of the value of that at the center grid point. This gives an approximation of the scales included by truncating a field at T20.

The standard deviations of 10-30-day OLR (shaded) and divergence (contoured) are shown in Fig. 6. OLR and divergence fields are relatively consistent. The largest values in both fields occur south of the Amazon in southeast Brazil and seem to be associated with variations in the South Atlantic convergence zone. Variations are smaller over the Amazon. The standard deviation increases to the east in divergence, while OLR exhibits a minimum in variation in the northwest and central Amazon where the time mean OLR is lowest (see Fig. 1). The standard deviation of NCEP precipitation (not shown) is qualitatively similar to that of divergence, with low values in the southwest Amazon and an increase to the southeast.

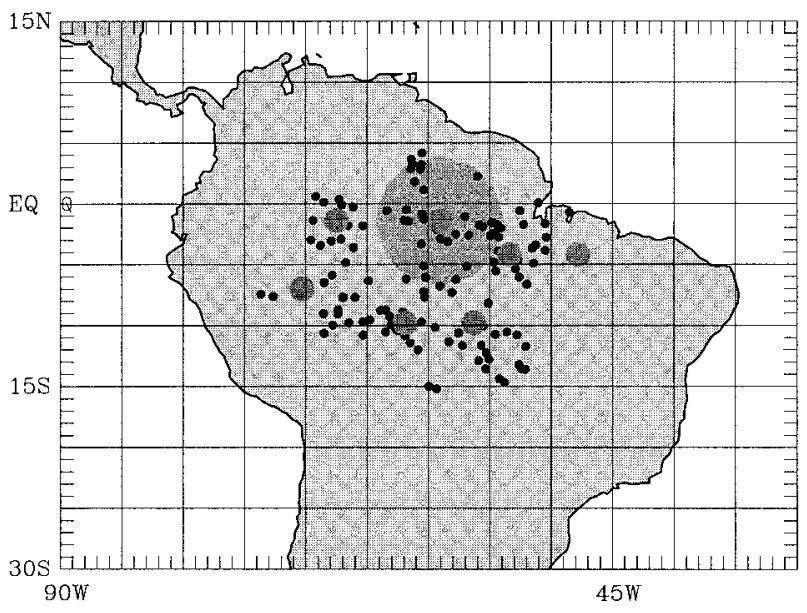

FIG. 5. Grid points at which OLR and divergence are compared (shaded circles), and sites at which rainfall is observed (dots). Locations of grid points for comparison are Manaus $\left(1.4^{\circ} \mathrm{S}, 59.1^{\circ} \mathrm{W}\right)$, northwest $\left(1.4^{\circ} \mathrm{S}, 67.5^{\circ} \mathrm{W}\right)$, southeast $\left(9.8^{\circ} \mathrm{S}, 56.3^{\circ} \mathrm{W}\right)$, southwest $\left(7.0^{\circ} \mathrm{S}, 70.3^{\circ} \mathrm{W}\right)$, and near the mouth of the Amazon $\left(4.2^{\circ} \mathrm{S}, 53.4^{\circ} \mathrm{W}\right)$. Large shaded circle is obtained by setting field to zero, except for the grid point at the center of the circle, then truncating the field spectrally at T20. Shading includes grid points at which value is half the truncated value at the center of the circle.

Figure 7 shows the average correlation ${ }^{1}$ between divergence at each available pressure level and observed rainfall, OLR, and NCEP precipitation for each of the sites shown in Fig. 5. Observed rainfall includes stations averaged within $7^{\circ}$ of the base point and the gridded variables are truncated at T20. Correlations are largest in an absolute sense at either 850 or $150 \mathrm{mb}$. The correlations at those levels between model-derived precipitation and divergence are larger than are the other quantities with divergence. OLR is best correlated with 150$\mathrm{mb}$ divergence, while rainfall is best correlated with 850-mb divergence, although the correlation with rainfall is everywhere weak. Further discussion will consider divergence at either 150 or $850 \mathrm{mb}$.

The correlation between 150-mb divergence and OLR as a function of spatial scale is shown in Fig. 8. There is a near-linear decrease in correlation with decreasing scale, starting at about wavenumber 9. At smaller scales, the correlation is slightly better in the north and east Amazon. Although the correlation of the annual cycles at the site near Manaus was distinctly lower than at other locations (see discussion of Figs. 2 and 3), the same location is well correlated on the 10-30-day scale. The correlation as a function of scale between OLR and NCEP precipitation (not shown) is similar but slightly lower at each wavenumber than that between OLR and 150 -mb divergence. The rest of this study will consider fields truncated at T20.

\footnotetext{
${ }^{1}$ Average correlation is defined here as \pm the square root of the average variance explained.
} 


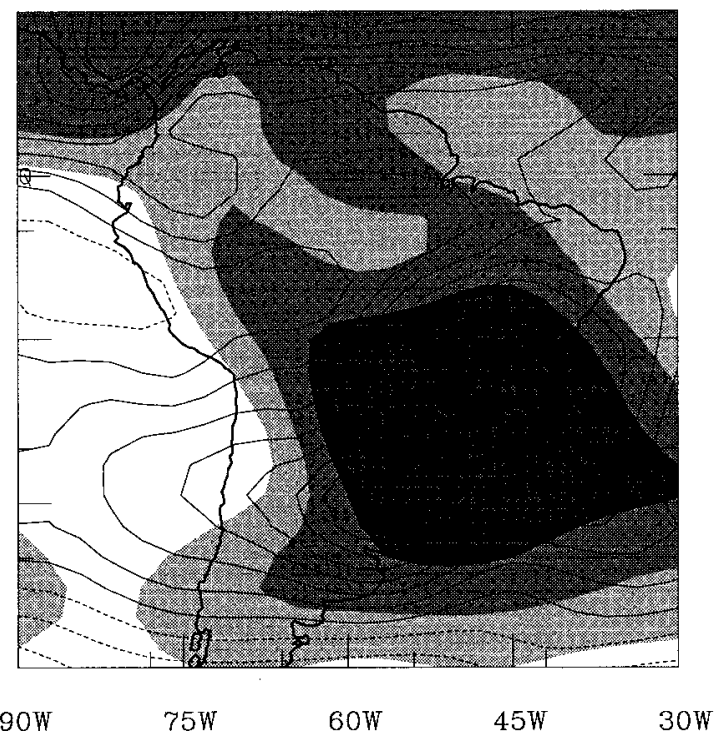

$15 \mathrm{~N}$

FIG. 6. Standard deviation of 10-30-day filtered OLR (shaded) and divergence (countoured). Light shading includes values greater than $8 \mathrm{~W} \mathrm{~m}^{-2}$, medium shading greater than $10 \mathrm{~W} \mathrm{~m}^{-2}$, and dark shading greater than $12 \mathrm{~W} \mathrm{~m}^{-2}$. Contours are at intervals of $1 \times 10^{7} \mathrm{~s}^{-1}$ with contours less than $12 \times 10^{7} \mathrm{~s}^{-1}$ dashed.

Figure 9a shows the correlation of 10-30-day filtered rainfall that has been averaged within a circle of a given radius with OLR, divergence, and NCEP precipitation, all truncated at T20 at the point near Manaus. The correlation between OLR and rainfall peaks at a radius of $5^{\circ}$. The correlation between divergence at either level and rainfall is much smaller but tends to remain about the same with increasing radius, even when the radius is clearly larger than the scale represented by a grid point in a field truncated at T20. On the other hand, the correlation of OLR or divergence with rainfall at a fixed radius of $5^{\circ}$ or $7^{\circ}$ decreases slightly as the scale increases from T20 to T15.

Although observed rainfall and OLR are relatively well correlated, the majority of variance in one field is still not explained by the other. It is not clear what fraction of this unexplained variance is due to inadequate spatial sampling of rainfall. To estimate the number of stations necessary to adequately represent an areal average of rainfall, and to show that it is appropriate to compare a $5^{\circ}$ radius circle with T20 gridded data, we correlate 10-30-day OLR at T20 with rainfall within $3^{\circ}, 4^{\circ}, 5^{\circ}$, and $7^{\circ}$ radii as a function of the number of stations included. Because of the enormous number of possible combinations, we average no more than 10000 combinations (randomly chosen) for a given number of stations. The average correlations are shown in Fig. 9b.

It appears from this figure that the true correlation between OLR and rainfall on this timescale is larger than that calculated at any radius, due to inadequate spatial sampling. Extrapolation of the $5^{\circ}$ curve suggests that about 50 stations would be needed to achieve a

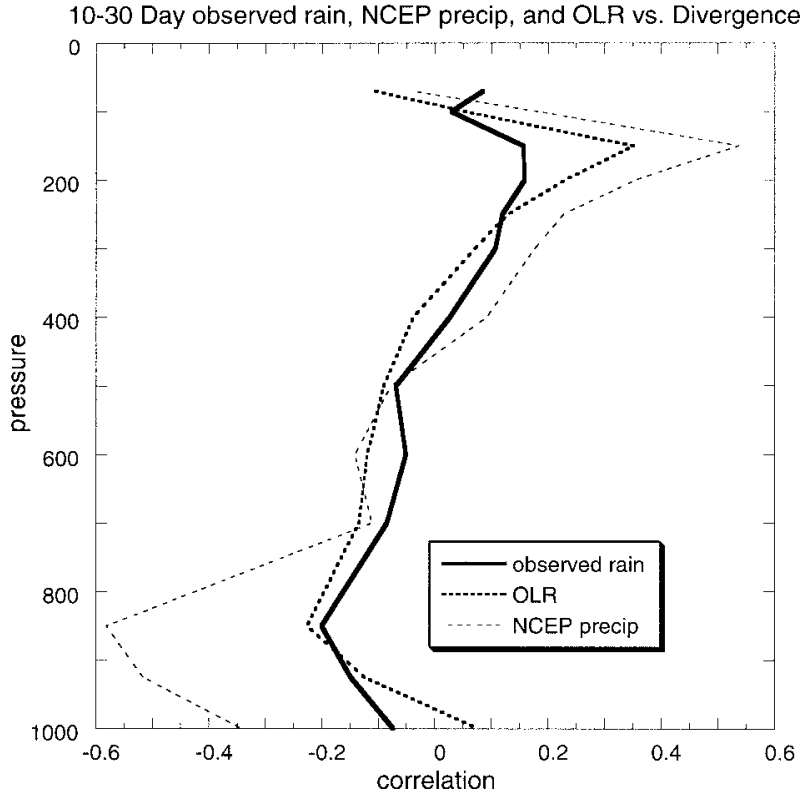

FIG. 7. Average correlation (see footnote) between divergence at each available pressure level (mb) and model precipitation, OLR, and observed rainfall for each of the points shown in Fig. 5. Fields are truncated at T20 and filtered to include periods of 10-30 days before computing correlations. Observed rainfall is the average of stations within $5^{\circ}$ of center point.

maximum possible correlation of about 0.63 . This implies a needed density of one station per $20000 \mathrm{~km}^{2}$.

Although by extrapolation to an unlimited number of stations, the correlation at $5^{\circ}$ and $4^{\circ}$ would appear to be about the same, the correlation is better at a radius of $5^{\circ}$ than $4^{\circ}$ because there are more stations. For a given number of stations, the correlation is better at $4^{\circ}$. A

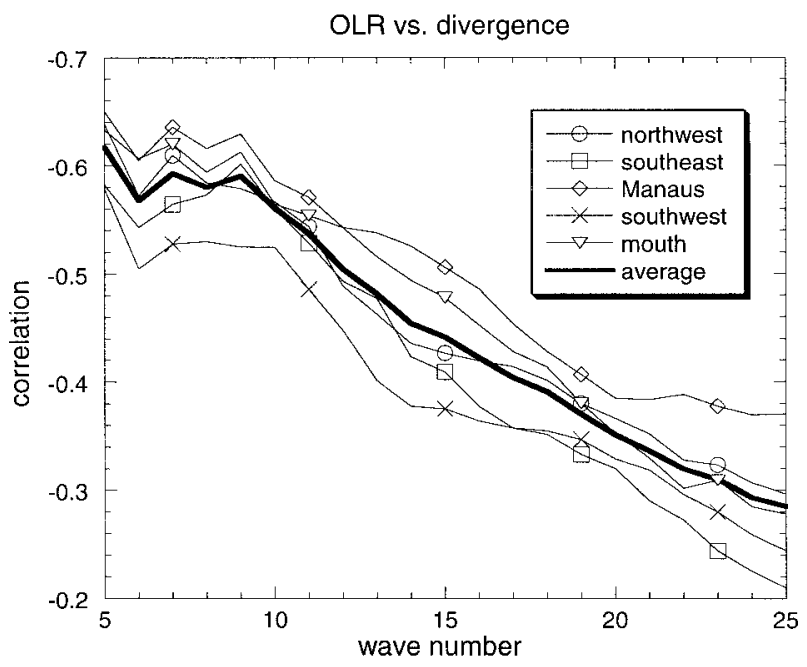

FIG. 8. Correlation between $150-\mathrm{mb}$ divergence and OLR as a function of spatial scale. Abscissa denotes total wavenumber at which each field was truncated prior to computing correlation. Fields are filtered to include periods of 10-30 days. 
(a) rainfall vs. OLR, divergence, and NCEP precip
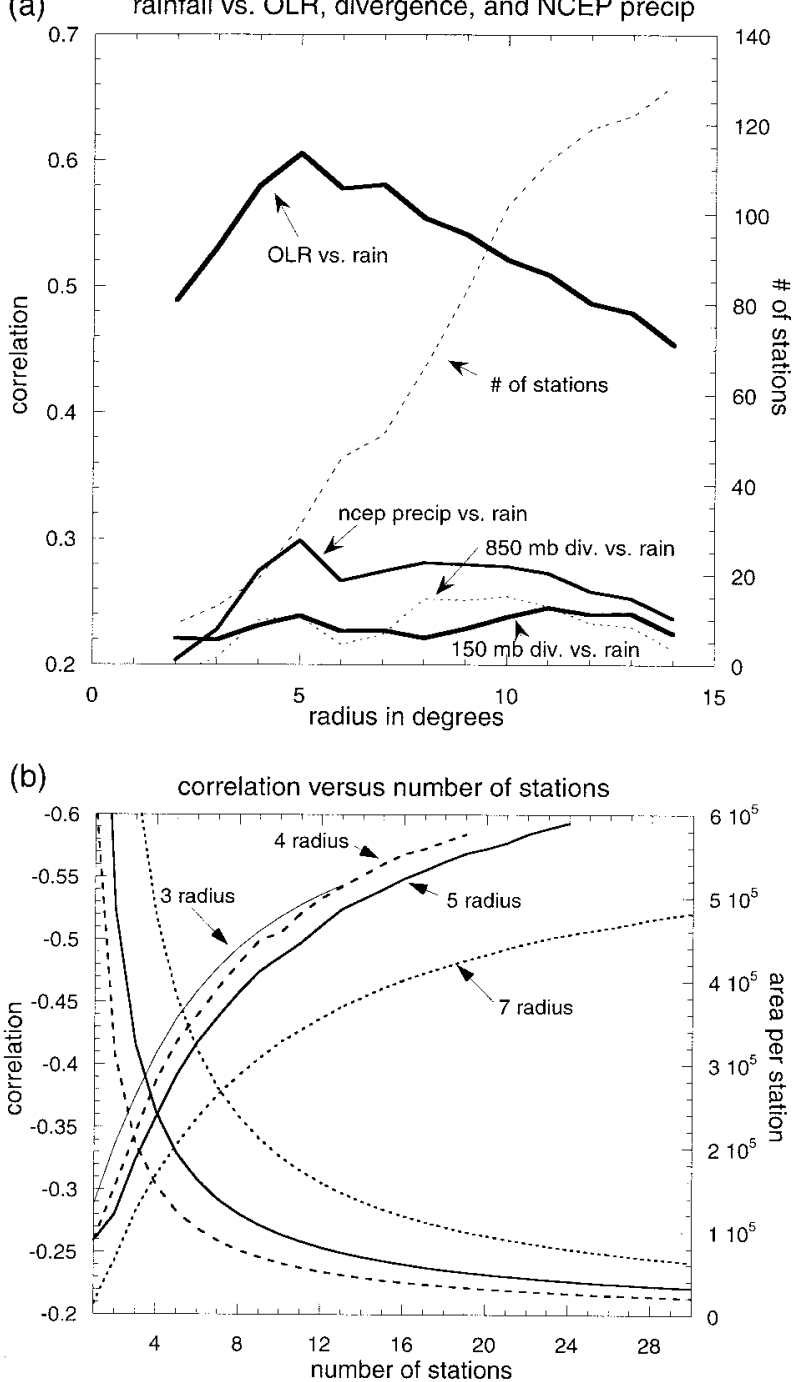

FIG. 9. (a) Rainfall averaged among stations that lie within a given radius (abscissa) of point near Manaus correlated with $150-\mathrm{mb}$ divergence, 850-mb divergence, OLR, and model precipitation at same point. Also shown are number of sites at which rainfall is observed within each radius. Divergence and OLR are truncated at T20, and all series are filtered to include periods of 10-30 days prior to computing correlation. (b) Correlation of OLR at T20 versus number of stations included within different radii (marked). Both OLR point and radius center are at $1.4^{\circ} \mathrm{S}, 59.1^{\circ} \mathrm{W}$. Up to 10000 combinations are averaged (see footnote) to obtain each correlation coefficient. Scale at right denotes average area $\left(\mathrm{km}^{2}\right)$ per station included (unmarked curves, but same style as radius to which it corresponds). Stations included in a given calculation are averaged into pentads then filtered to include periods of 10-30 days prior to computing correlations.

radius of $3^{\circ}$ would appear to asymptote at a smaller absolute correlation than would $4^{\circ}$ or $5^{\circ}$. We choose a radius of $5^{\circ}$ because for a given density of stations the correlation is larger than at $4^{\circ}$.

Conversely, if one compares the $7^{\circ}$ and $5^{\circ}$ radii curves, it is seen that although the $5^{\circ}$ correlation is larger for a given number of stations and the asymp-

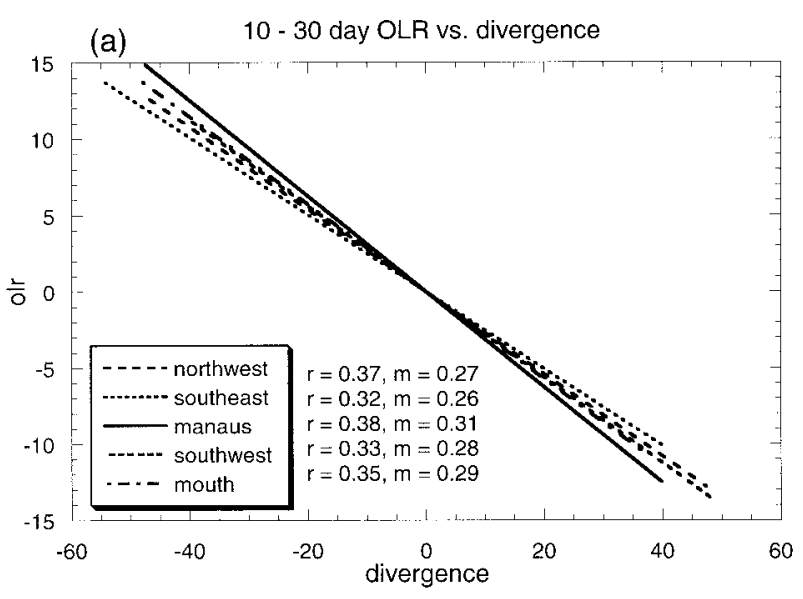

(b) 10 - 30 day observed rain vs. ncep precipitation

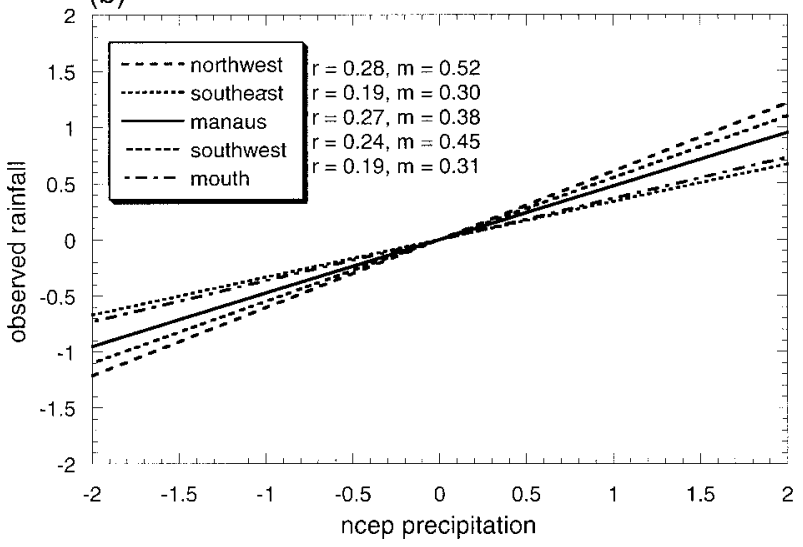

FIG. 10. Best linear fit between (a) OLR and 150-mb divergence, and (b) observed rainfall and model precipitation. Gridded fields are truncated at T20, rainfall is an average within a $5^{\circ}$ radius circle, and all series are filtered to include periods of 10-30 days prior to computing regression.

tote value appears to be higher at $5^{\circ}$ (note that the $5^{\circ}$ correlations are better than at $7^{\circ}$ when all stations are included; see Fig. 9a), correlations are about equal for the same density of stations. This suggests that adequate spatial sampling is more important that an exact match of area.

The best linear fit between OLR and divergence for each of the sites is shown in Fig. 10a. Although there is large scatter (i.e., never more than $16 \%$ of the variance explained), there is a remarkable similarity between each of the slopes. The difference between the maximum and minimum slope divided by the mean slope of the five curves is just $21.5 \%$. Although the largest correlations among the relevant variables are between OLR and rainfall (not shown), best-fit slopes at the different sites are more varied than those for the OLR-divergence comparison. The slope is more variable and the correlations are slightly smaller if 150 -mb divergence is replaced by NCEP precipitation (not shown). 
2 - $1 \emptyset$ day OLR vs. NCEP Precip

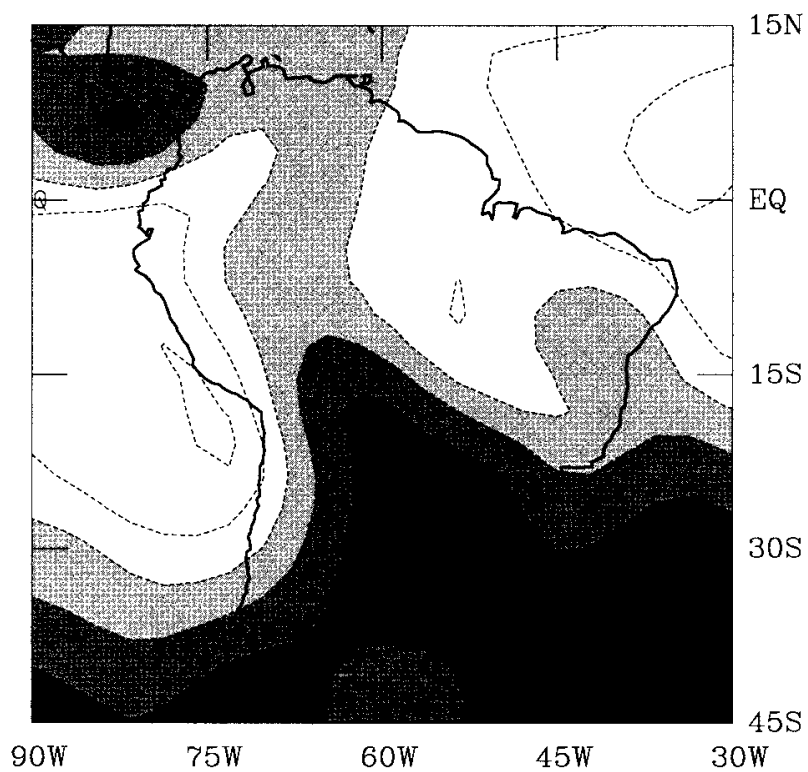

FIG. 11. Correlation between OLR and NCEP precipitation. Prior to calculating correlations, daily average fields are truncated at T20, and then passed through a 61-point Lanczos filter with the low-frequency half-power at 10 days. Dark shading represents correlations less than -0.5 , medium shading from -0.4 to -0.5 , and light shading from -0.3 to -0.4 . Contour interval is 0.1 .

Figure 10b shows the linear fits between observed rainfall (using stations within a $7^{\circ}$ radius circle) and NCEP precipitation (truncated at T20). The correlations are quite small. Surprisingly, at each point the best-fit slope is near 0.5 , meaning that a $1-\mathrm{mm}$ observed anomaly predicts at least $2 \mathrm{~mm}$ in NCEP precipitation. In the annual cycle, variations in observed rainfall are larger than those in NCEP precipitation (see Fig. 3).

\section{c. The 2-10-day comparison}

OLR and model precipitation are spatially truncated at T20, temporally high-pass filtered with a Lanczos filter with half power at 10 days, and then correlated. The correlations are shown in Fig. 11. The highest correlations are away from the Tropics, but correlations in the western Amazon are relatively large, exceeding 0.3. The correlation at a given point between these two quantities is only slightly smaller that in the 10-30-day band and larger than the 2-10-day 150 -mb divergence-OLR correlation. Lead and lag correlations are smaller than simultaneous correlations. Correlations improve by about 0.1 at the T15 spatial scale. At $200 \mathrm{mb}$, correlations over the Amazon Basin are slightly smaller than at $150 \mathrm{mb}$.

\section{d. Diurnal variability}

The diurnal cycle is a dominant feature of the variability over the South American region, as is obvious from an inspection of geostationary satellite imagery. An inadequate representation of the diurnal cycle will result in errors in variability on other scales, including the time mean.

Figure 12 shows the composite hourly rainfall for the available record for each of the ABRACOS sites. The site at Ji-Paraná is close to the southwestern border of the tropical rain forest and has a pronounced dry season between June and August. The dry season at Marabá, near the eastern edge of the Amazon forest, is from June to September. Manaus, in central Amazonia, has a maximum from March to April with a minimum from July to September.

The rainfall maxima at Ji-Paraná and Manaus occur between 1400 and 1800 local standard time (LST), corresponding to 1800 and 2100 UTC. Lloyd (1990) found a similar diurnal phase at Manaus. Marengo (1995) found a maximum of deep convection at 1800 UTC. At Marabá, however, there is a weak, broad maximum between 0200 and 1000 LST (0500 and 1300 UTC, with an even weaker secondary maximum at around 1800 LST). The nighttime maximum at Marabá has been attributed to its relative proximity to the coast. Within a few hundred kilometers of the coast there is a nocturnal maximum in low-level convergence associated with a land-sea breeze (e.g., Kousky 1980).

The composite 150-mb divergence for each of the four analysis times is shown in Fig. 13. There is large diurnal variation. The largest mean divergence over the Amazon is at 0000 UTC, with a minimum at 1200 UTC, consistent with the results of Kousky and Bell (1996). Divergence appears to be decreasing at 0600 UTC, and the maximum for that time is over the western Amazon. There is a peak near the mouth of the Amazon at 1800 UTC. These maps are consistent with the observation that convection is initiated near the mouth of the Amazon (Fig. 12d) and then propagates toward the west (e.g., Molion 1987).

At Ji-Paraná and Manaus, rainfall peaks a few hours before the peak in divergence, which is consistent if one believes that heating, which is directly tied to rainfall, eventually forces large-scale divergence. At the Marabá site, which is directly beneath the divergence maximum at 1800 UTC, maximum rainfall occurs some $7 \mathrm{~h}$ before that. Thus, while divergence and rainfall at the interior ABRACOS sites are consistent in that maxima in rainfall occur a few hours before the maxima in upper-level divergence, there would appear to be a phasing problem nearer the coast. It is possible that the coastal regime is not adequately represented by the relatively large spatial scales (T20) shown here.

Previous studies have cast doubt on the validity of the divergence fields because of their inconsistency with NCEP rainfall and OLR obtained from geostationary 


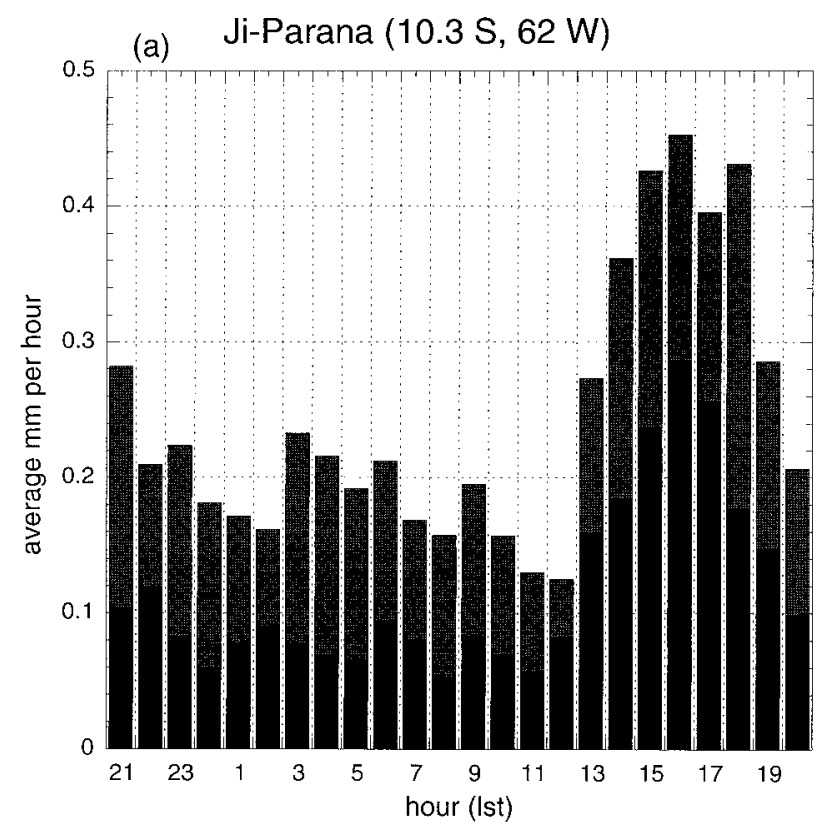

(b)

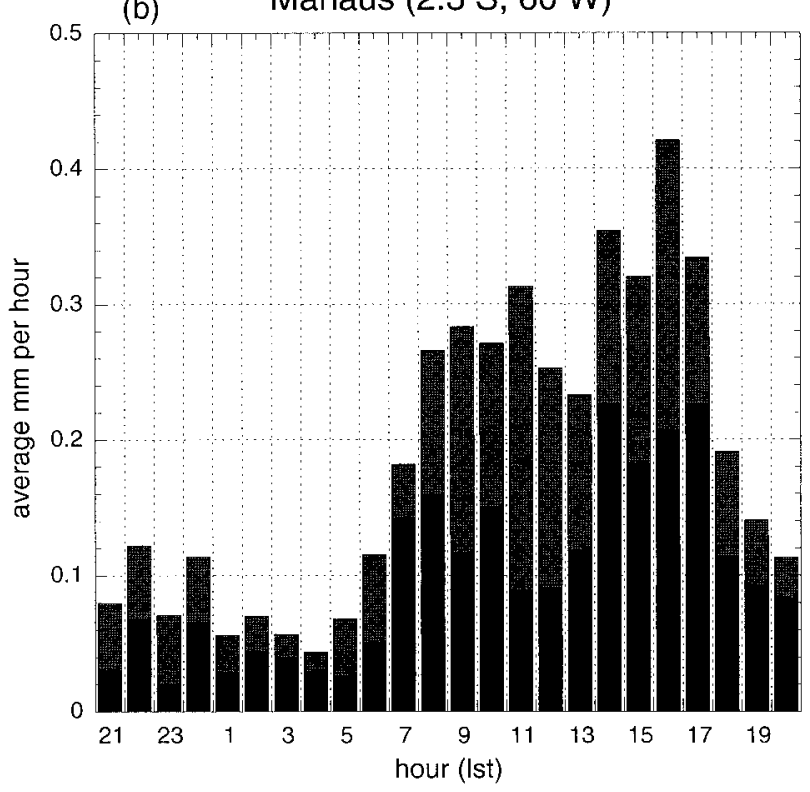

satellites (G. D. Bell 1997, personal communication). Based on these studies, the next version of the reanalysis will include a radiation package that is called hourly, instead of at 6-h intervals as at present (G. D. Bell 1997, personal communication).

\section{Conclusions}

Correlations between OLR, divergence, and rainfall are not large on submonthly timescales. The best predictor of observed rainfall is OLR, which can explain more than $35 \%$ of the 10-30-day filtered variance at

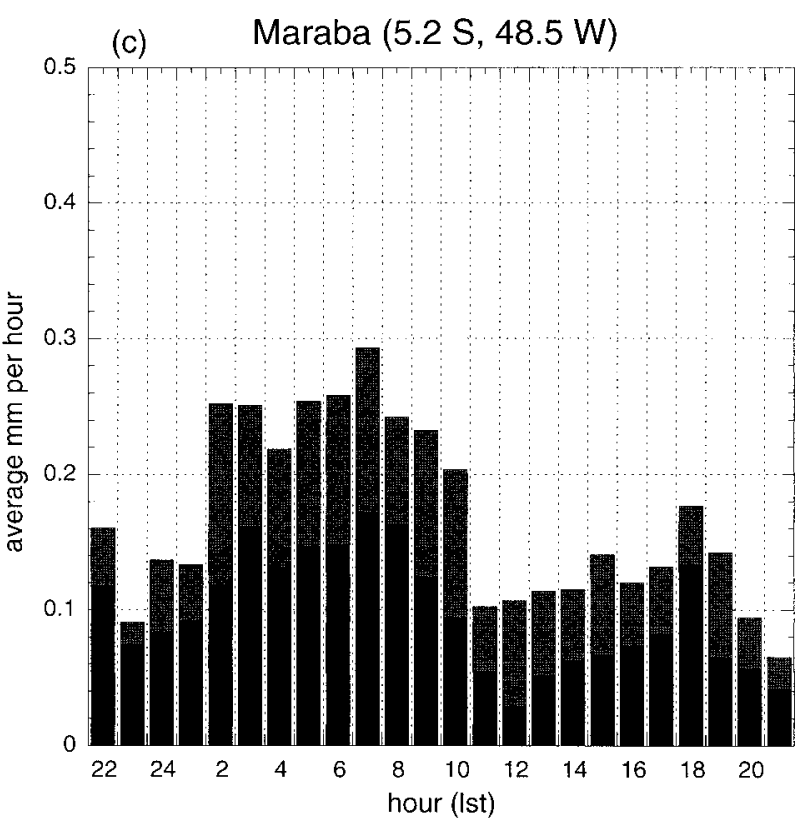

FIG. 12. Composite of rainfall for each hour at ABRACOS sites of (a) Ji-Paraná, (b) Manaus, and (c) Marabá. Value shown is average of two nearby locations representing pasture and the top of the forest canopy. Contribution from pasture is shown as dark bar (actual value divided by two) and from forest is shown as light bar. Approximate locations are shown at top of each panel. Left edges of abscissas start at 0100 UTC, although they are labeled in local standard time. some spatial scales (see Fig. 9). Part of the problem is due to inadequate spatial sampling of rainfall. Correlations between observed rainfall and model quantities (precipitation or divergence) are quite small, which is unfortunate, as it would be useful to be able to quantitatively estimate short-term precipitation variability using the model variables, which will eventually extend backward to times when direct observations of rainfall are few.

It is somewhat encouraging that relationships are always of the expected sign and that the value of their respective correlations are as one would anticipate. For 
$15 \emptyset \mathrm{mb}$ Divergence $\emptyset z$

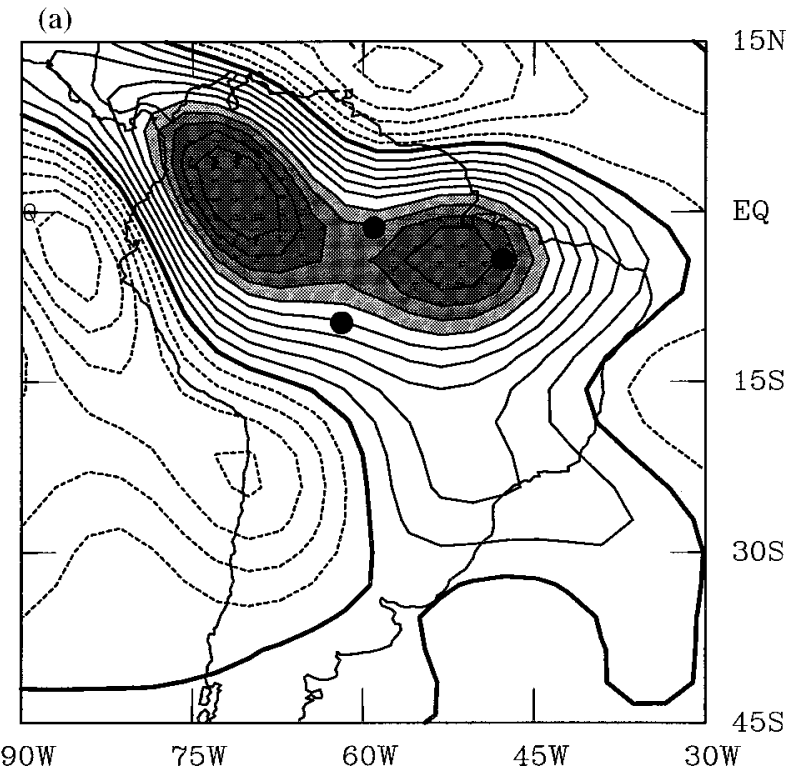

$150 \mathrm{mb}$ Divergence $6 z$

(b)

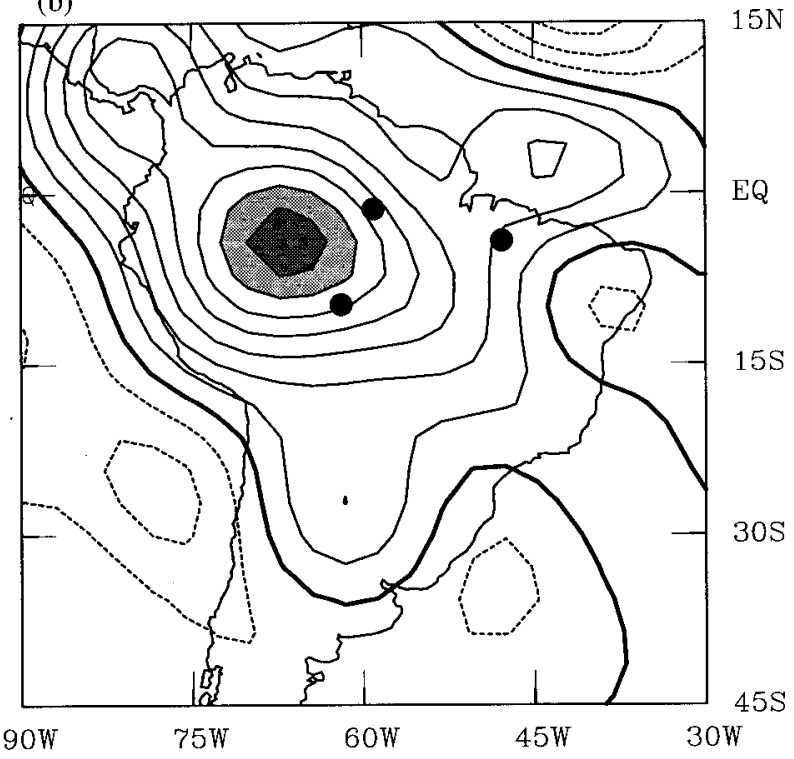

$150 \mathrm{mb}$ Divergence $12 \mathrm{z}$

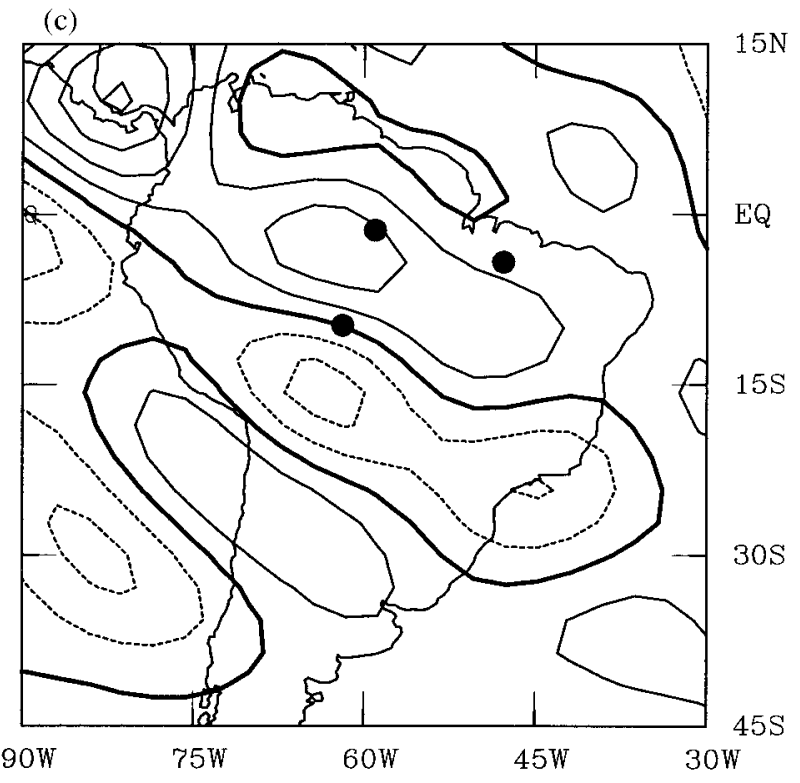

$150 \mathrm{mb}$ Divergence $18 \mathrm{z}$

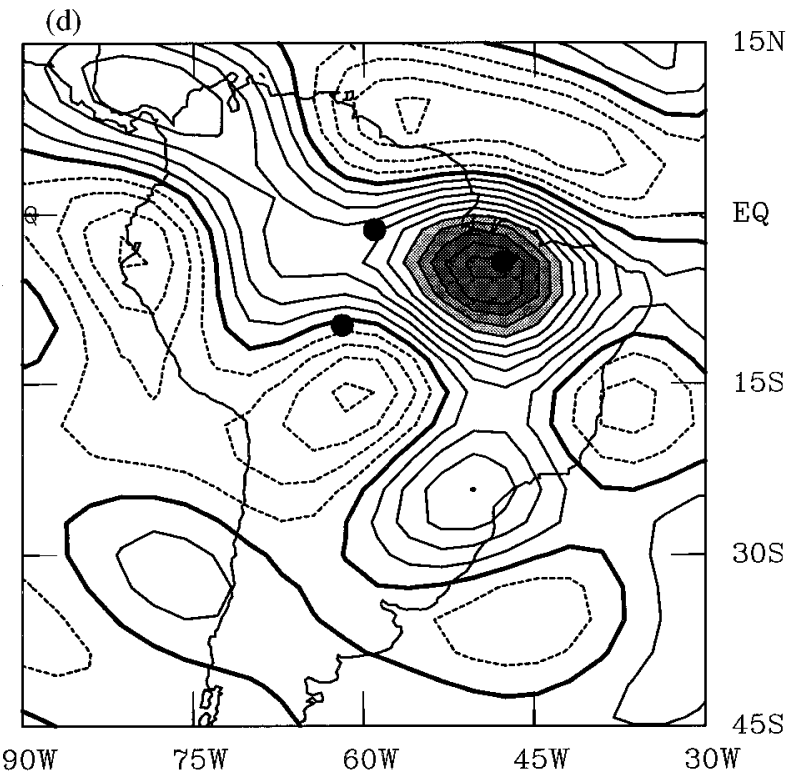

FIG. 13. A 150-mb divergence composited at (a) 0000, (b) 0600, (c) 1200, and (d) 1800 UTC. Fields are truncated at T20. Dark circles show approximate location of ABRACOS sites. Contour interval is $10^{-6}$, with negative values dashed and zero contour thick. Shading begins at $6 \times 10^{-6}$.

example, OLR and 150-mb divergence generally are better correlated than OLR and model precipitation. Yet observed rainfall is better correlated with model precipitation than with upper-level divergence.

On the other hand, it is possible that the large, singular events that mark the seasonal transition from one regime to another (i.e., from the dry season to the rainy season) may be consistent among different approximations for rainfall. Figures 14 and 15 show time series of such measures for 1985 and 1979.

Figure 14a shows time series of OLR, 150-mb divergence, observed rainfall, and NCEP precipitation for the latter part of 1985 at the location near Manaus. An abrupt transition in OLR occurs around pentad 59 (centered on 20 October). Divergence peaks on the next pentad. A few pentads later, rainfall begins a less ob- 

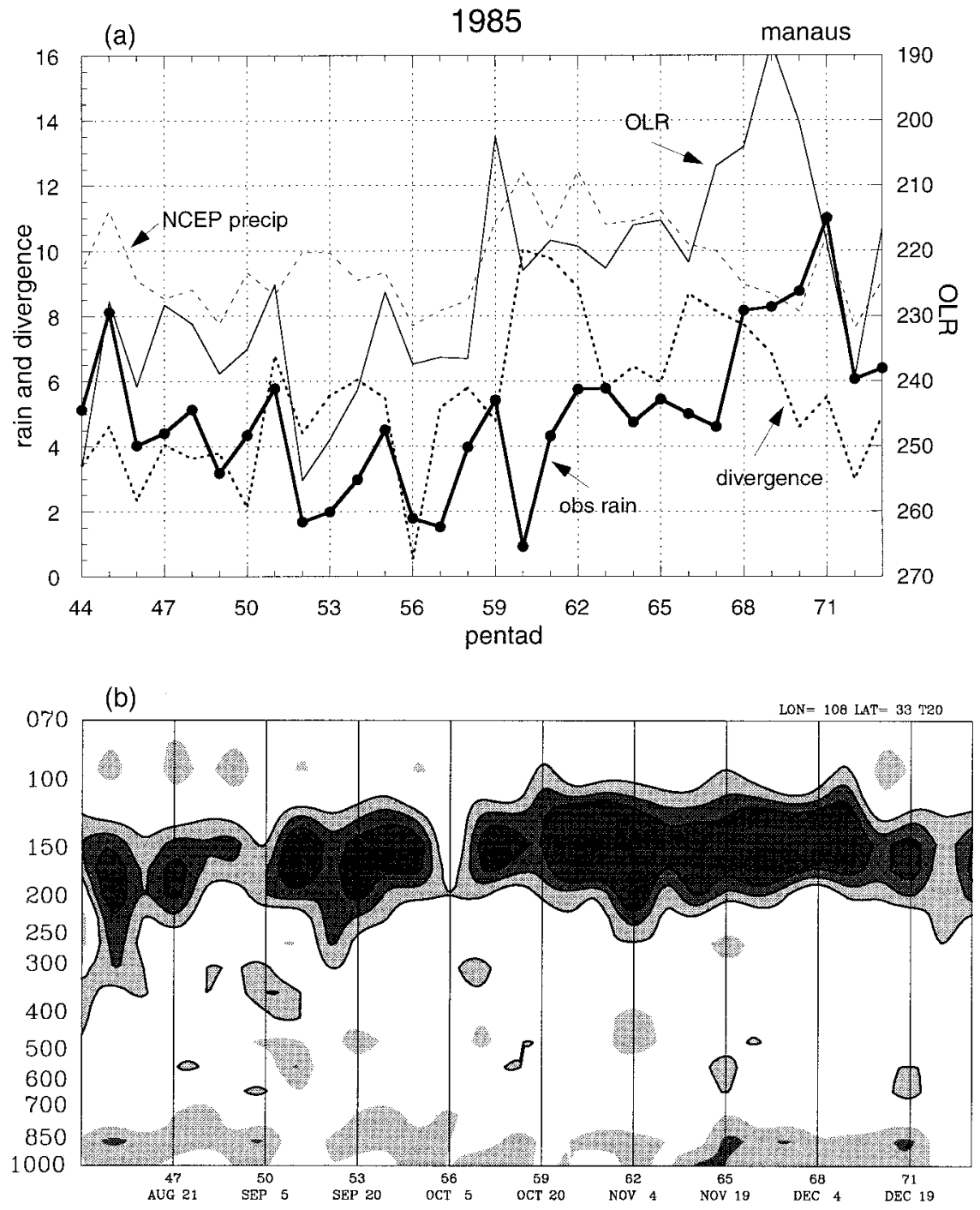

FIG. 14. (a) Pentad series of average daily rainfall for stations within a radius of $5^{\circ}(\mathrm{mm}$ per day, scale at left), OLR at T20 (W m ${ }^{-2}$, scale at right), 150-mb divergence at T20 $\left(\times 10^{-6} \mathrm{~s}^{-1}\right.$, scale at left), and model precipitation (mm per day, scale at left). Series extends from pentad centered on 6 August 1985 to that centered on 29 December 1985. (b) Time-height section of pentad divergence at T20 for the same location and times as in (a). Shading starts at $1.875 \times 10^{-6}$, with an interval of $1.25 \times 10^{-6}$. Positive values have contour curves between increments of shading.

vious transition toward higher values, although if one were defining onset by rainfall alone it would be tempting to choose a pentad near 68 (centered on 4 December). Divergence agrees with OLR within a pentad, although its value does not remain as elevated for as long as OLR; in particular, there is a discrepancy around pentad 70. Figure 14b, however, and in which a timeheight section of divergence is plotted, clearly shows onset throughout a deep layer around pentad 59, in perfect agreement with OLR. Although model precipitation correlates with observed rainfall better than divergence on all but the largest spatial scales, there is little indication of onset in that field, and the variations clearly are too small when compared to observed rainfall.
Figure 15 shows the same quantities plotted for 1979. In retrospect, both OLR and 150 -mb divergence would have picked out the onset of the rainy season reasonably well. NCEP precipitation again is woefully lacking. It is worth noting that although 1985 was a wet year and 1979 a dry year in Amazonia and northeast Brazil, onset occurs near Manaus at about the same date in each year.

In summary, OLR is by far a better predictor of observed rainfall than either divergence or model precipitation. This is true of the annual cycle and 10-30 day bandpassed data. It is also true that in many years, OLR and observed rainfall are in near agreement as to the date of transition to the rainy season, while the 


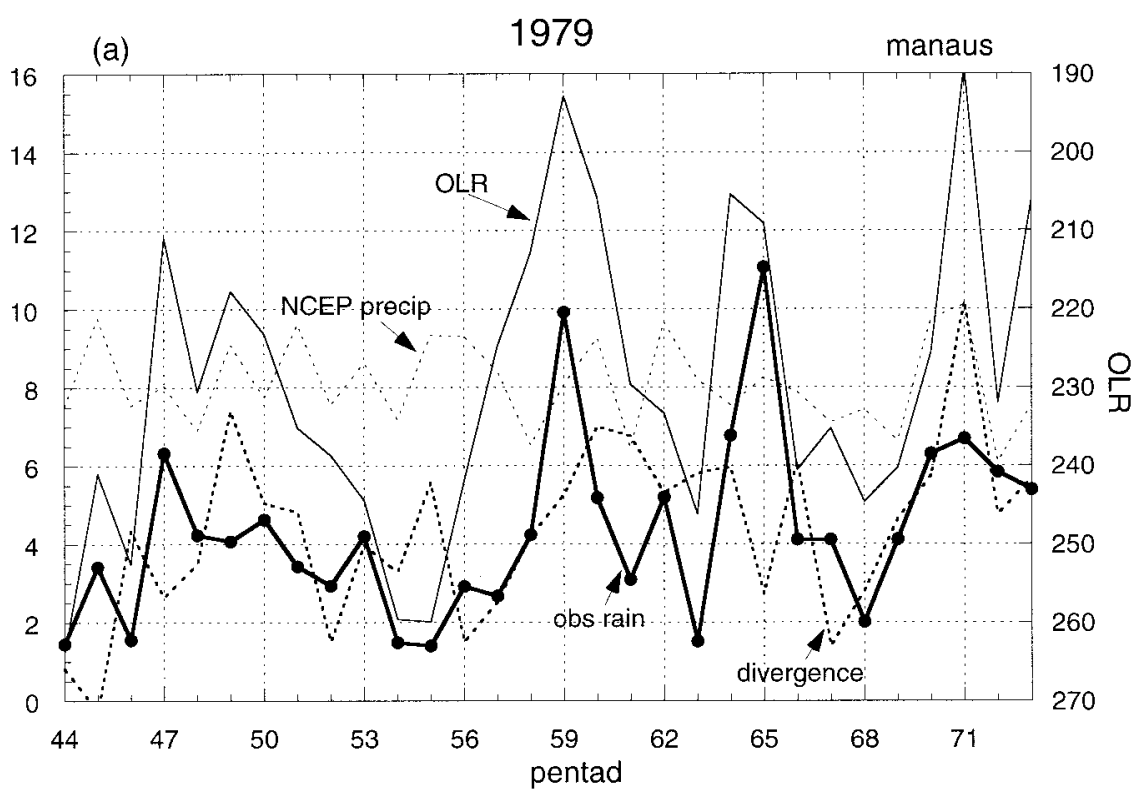

(b)

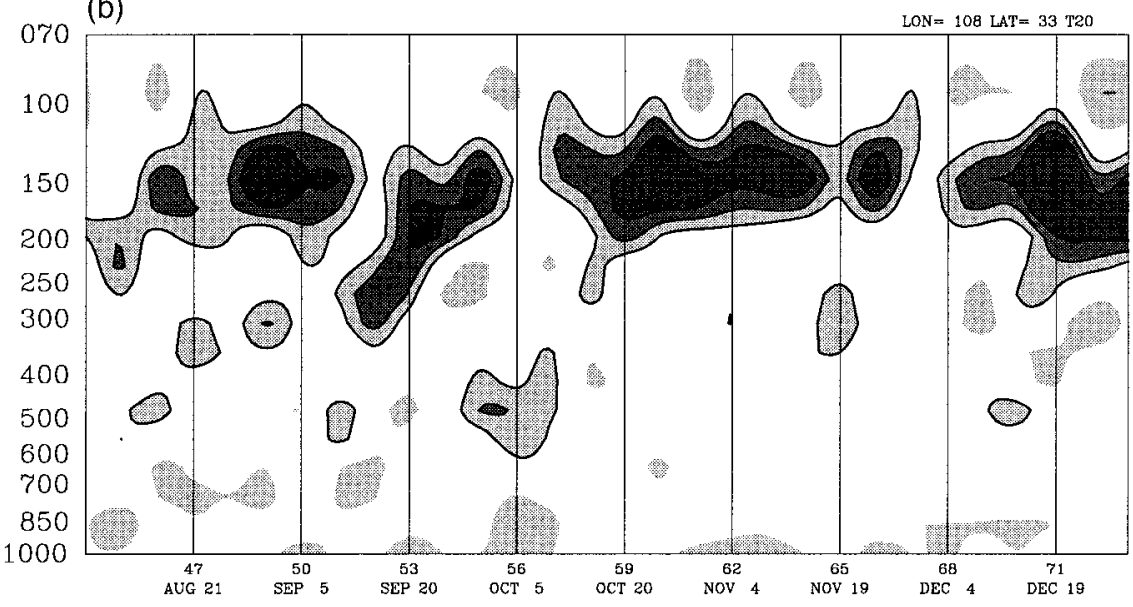

FIG. 15. As in Fig. 14 except for 1979.

model quantities do not well represent the transition. The mean diurnal cycles of $150-\mathrm{mb}$ divergence and rainfall are consistent except near the mouth of the Amazon.

Acknowledgments. The authors wish to acknowledge the support from the NOAA Office of Global Programs (PAC Grant GC96-496) and the Inter-American Institute for Global Change Research (IAI). We are grateful for rainfall data provided by the Brasilian National Agency for Electric Energy (ANEEL).

\section{REFERENCES}

Adler, R. F., G. J. Huffman, and P. R. Keehn, 1994: Global rain estimates from microwave-adjusted geosynchronous IR data. $R e$ mote Sens. Rev., 11, 125-152.

Arkin, P. A., and B. N. Meisner, 1987: The relationship between large- scale convective rainfall and cold cloud over the Western Hemisphere during 1982-84. Mon. Wea. Rev., 115, 51-73.

Chelliah, M., J. E. Schemm, and H. M. Van den Dool, 1988: The impact of low-latitude anomalous forcing on local and remote circulation: Winters 1978/79-1986/87. J. Climate, 1, 11381152.

Duchon, C. E., 1979: Lanczos filtering in one and two dimensions. J. Appl. Meteor., 18, 1016-1022.

Horel, J. D., A. N. Hahmann, and J. E. Geisler, 1989: An investigation of the annual cycle of convective activity over the tropical Americas. J. Climate, 2, 1388-1403.

Hudlow, M. D., 1979: Mean rainfall patterns for the three phases of GATE. J. Appl. Meteor., 18, 1656-1669.

Huffman, G. J., R. F. Adler, B. Rudolf, U. Schneider, and P. R. Keehn, 1995: Global precipitation estimates based on a technique for combining satellite-based estimates, rain gauge analysis, and NWP model precipitation information. J. Climate, 8, 1284-1295.

Kalnay, E., and Coauthors, 1996: The NCEP/NCAR 40-year reanalysis project. Bull. Amer. Meteor. Soc., 77, 437-471.

Kousky, V. E., 1980: Diurnal rainfall variation in northeast Brazil. Mon. Wea. Rev., 108, 488-498. 
1988: Pentad outgoing longwave radiation climatology for the South American sector. Rev. Bras. Meteor., 3, 217-231.

_ as depicted in the NCAR/NMC reanalysis data. Preprints, Eighth Conf. on Global Ocean-Atmosphere-Land System (GOALS), Atlanta, GA, Amer. Meteor. Soc., 395-399.

Liebmann, B., and C. A. Smith, 1996: Description of a complete (interpolated) outgoing longwave radiation dataset. Bull. Amer. Meteor. Soc., 77, 1275-1277.

Lloyd, C. R., 1990: The temporal distribution of Amazonian rainfall and its implications for forest interception. Quart. J. Roy. Me teor. Soc., 116, 1487-1494.

Marengo, J. A., 1995: Interannual variability of deep convection over the tropical South American sector as deduced from ISCCP C2 data. Int. J. Climatol., 15, 995-1010.

Molion, L. C. B., 1987: On the dynamic climatology of the Amazon basin and associated rain-producing mechanisms. The Geophysiology of Amazonia, R. Dickinson, Ed., John Wiley and Sons, 391-407.

Morressey, M. L., 1986: A statistical analysis of the relationships among rainfall, outgoing longwave radiation and the moisture budget during January-March 1979. Mon. Wea. Rev., 114, 931942.

Motell, C. E., and B. C. Weare, 1987: Estimating tropical Pacific rainfall using digital satellite data. J. Appl. Meteor., 26, 14361446.

Nobre, C. A., and Coauthors, 1996: The Large-scale Biosphere-Atmosphere Experiment in Amazonia (LBA).Concise experiment plan; LBA Science Planning Group, Staring Center-DLO, the Netherlands.

Sardeshmukh, P. D., and B. J. Hoskins, 1987: On the derivation of the divergent flow from the rotational flow: The chi problem. Quart. J. Roy. Meteor. Soc., 113, 339-360.

- and B. Liebmann, 1993: An assessment of low-frequency variability in the tropics as indicated by some proxies of tropical convection. J. Climate, 6, 569-575.

Shuttleworth, W. J., J. H. C. Gash, J. M. Roberts, C. A. Nobre, L. C. B. Molion, and N. M. G. Ribeiro, 1991: Post-deforestation Amazonian climate: Anglo-Brazilian research to improve prediction. J. Hydrol., 129, 71-86.

Trenberth, K. E., and J. G. Olson, 1988: An evaluation and intercomparison of global analyses from the National Meteorological Center and the European Centre for Medium-Range Weather Forecasts. Bull. Amer. Meteor. Soc., 69, 1047-1057.

Xie, P., and P. A. Arkin, 1998: Global monthly precipitation estimates from satellite-observed outgoing longwave radiation. J. Climate, 11, 137-164.

Yoo, J., and J. A. Carton, 1988: Spatial dependence of the relationship between rainfall and outgoing longwave radiation in the tropical Atlantic. J. Climate, 1, 1047-1054. 